\title{
Efficacy of the Osaka Medical College (OMC) brace in the treatment of adolescent idiopathic scoliosis following Scoliosis Research Society brace studies criteria
}

Hiroshi Kuroki ${ }^{*}$, Naoki Inomata² ${ }^{2}$ Hideaki Hamanaka², Kiyoshi Higa ${ }^{2}$, Etsuo Chosa ${ }^{2}$ and Naoya Tajima ${ }^{3}$

\begin{abstract}
Background: The efficacy of brace treatment for patients with adolescent idiopathic scoliosis (AIS) remains controversial. To make comparisons among studies more valid and reliable, the Scoliosis Research Society (SRS) has standardized criteria for brace studies in patients with AIS. The purpose of this study was to evaluate the efficacy of the Osaka Medical College (OMC) brace for AIS in accordance with the modified standardized criteria proposed by the SRS committee on bracing and non-operative management.

Methods: From 1999 through 2010, 31 consecutive patients with AIS who were newly prescribed the OMC brace and met the modified SRS criteria were studied. The study included 2 boys and 29 girls with a mean age of 12 years and 0 month. Patients were instructed to wear the brace for a minimum of 20 hours per day at the beginning of brace treatment. The mean duration of brace treatment was 4 years and 8 months. We examined the initial brace correction rate and the clinical outcomes of main curves evaluated by curve progression and surgical rate, and the compliance evaluated by the instruction adherence rate for all cases. The clinical course of the brace treatment was considered progression if $\geq 6^{\circ}$ curvature increase occurred and improvement if $\geq 6^{\circ}$ curvature decrease occurred according to SRS judgment criteria.
\end{abstract}

Results: The average initial brace correction rate was 46.8\%. In 10 cases the curve progressed, 6 cases the curve improved, and 15 cases the curve remained unchanged (success rate: 67.7\%). The mean instruction adherence rate, that was defined the percentage of the visits that patients declared they mostly followed our instruction to total visits, was $53.7 \%$. The success rate was statistically higher in the patient group whose instruction adherence rate was greater than $50 \%(88.2 \%)$ as compared with in those $50 \%$ or less (42.8\%).

Conclusions: OMC brace treatment for AIS patients could alter the natural history and significantly decreased the progression of curves to the threshold for surgical intervention. Better instruction adherence of brace wear associated with greater success.

Keywords: Adolescent idiopathic scoliosis (AIS), Osaka Medical College (OMC) brace, Conservative treatment, Hanging total spine $x$-ray, Standardized inclusion and assessment criteria, Scoliosis Research Society (SRS)

\footnotetext{
* Correspondence: hiroshik@med.miyazaki-u.ac.jp

${ }^{1}$ Department of Orthopaedic Surgery, National Hospital Organization

Miyazaki Higashi Hospital, 4374-1 Tayoshi Ooaza, Miyazaki 880-0911, Japan

Full list of author information is available at the end of the article
} 


\section{Introduction}

Operative treatment for adolescent idiopathic scoliosis (AIS) has been rapidly progressed as a result of the development of the spinal instrumentation that makes possible three-dimensional correction of spinal deformity [1-3]. However, the role of non-operative treatment is still indispensable for patients with mild to moderate AIS. Although in the past, numerous non-operative methods, including physical therapy, exercise, massage, manipulation, and electrical stimulation, have been attempted, brace treatment is generally perceived as the only potentially effective in preventing curve progression and the subsequent need for surgery $[4,5]$. Various types of brace have been invented and practically used for more than 50 years [6].

We usually use the Osaka Medical College (OMC) brace for the treatment of AIS patients who meet some requirements as follows; still under growing, a Cobb angle of between 25 and $50^{\circ}$, and an apex of caudad to $\mathrm{T} 7$, with expectation to halt the progression of curve and to improve cosmetic appearance. The OMC brace is one of the popular custom-made thoracolumbosacral orthoses (TLSOs) in Japan developed by Onomura in 1970's [7]. The characteristics of the OMC brace are represented by inconspicuous design, light weight, reduction of restriction on the chest wall movement, and ability to correct the high thoracic curve by righting reflex [7]. The concept of this brace is maintenance of whole body alignment and balance. For the achievement of these goals, step-by-step molding from pelvic girdle to high thoracic level with correcting lumbar and main thoracic curves is important to generate desirable corrective force based on the principle of three points lateral compression [8] (Figure 1).

Whereas, the efficacy of brace treatment for AIS continues to be controversial, with some authors reporting control of curve progression with bracing and others reporting that bracing fails to alter the natural history [9]. The lack of consistency of both the inclusion criteria and the definitions of brace effectiveness makes many clinicians skeptical about the efficacy of brace treatment [10].

To make comparisons among studies more valid and reliable, the Scoliosis Research Society (SRS) has standardized criteria for brace studies in patients with AIS [11].

The purpose of the present study was to evaluate the efficacy of the OMC brace for AIS patients in accordance with the new standardized criteria proposed by the SRS committee on bracing and non-operative management. The current report is the first detailed description focused on efficacy of OMC brace treatment for Japanese AIS patients based on SRS criteria.

\section{Materials and methods}

\section{Study overview}

Medical records and plain $\mathrm{x}$-rays of patients with AIS who were treated with the OMC brace were retrospectively reviewed. To be included in this study, patients met the following criteria: diagnosis of AIS with radiological

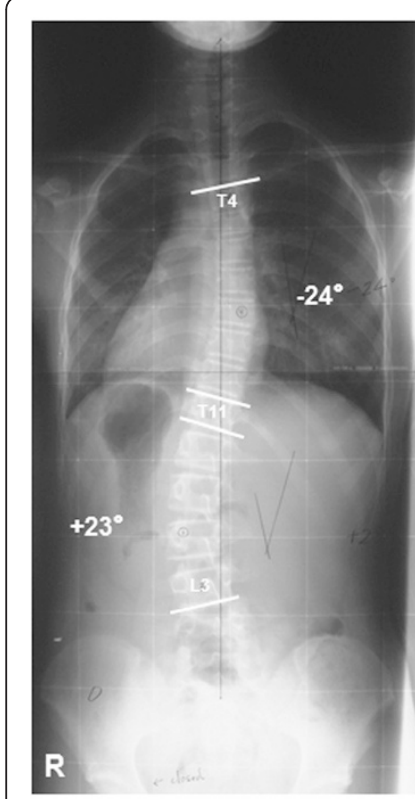

a

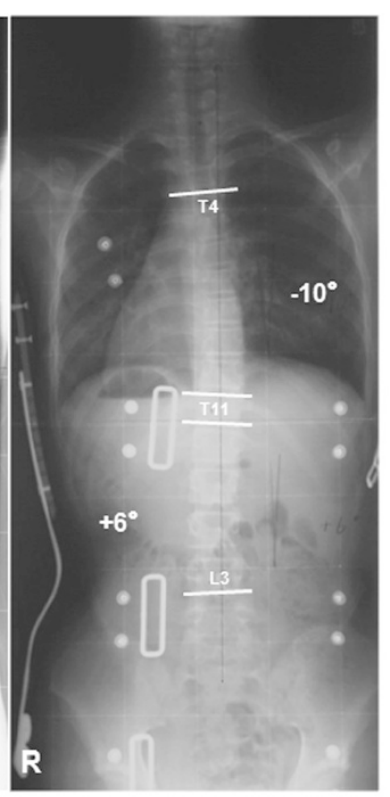

b

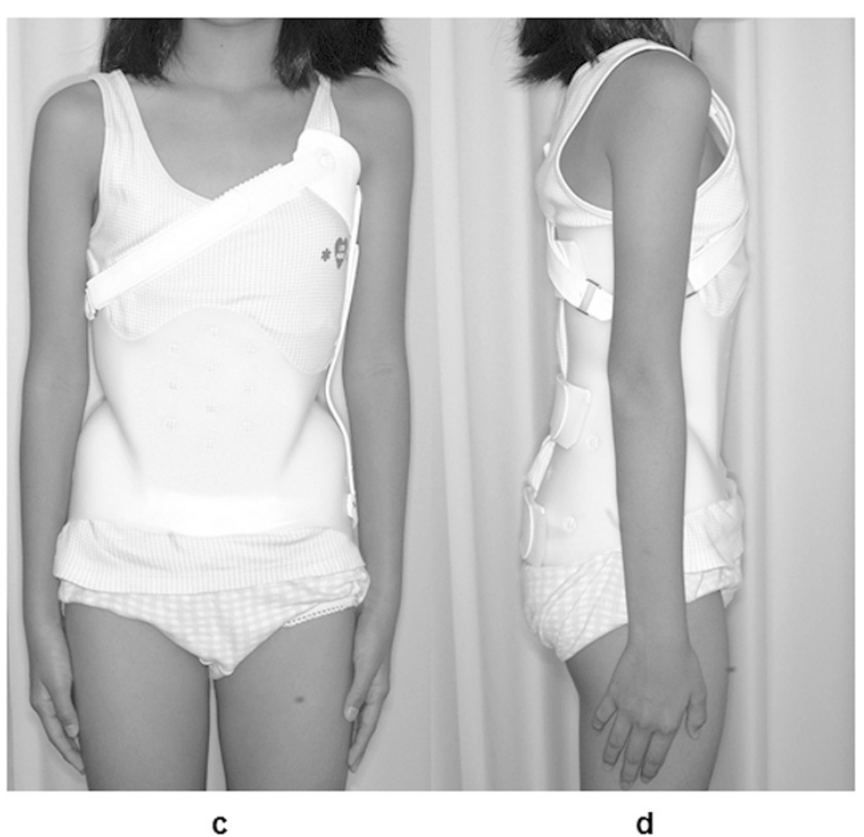

c d

Figure 1 Osaka Medical College (OMC) brace. The OMC brace satisfactorily corrects double major curves (a, b) and a standing posture in brace is well balanced (c, d). 
confirmation of absence of significant pathological malformation of the spine, age 10 years and older when their brace was prescribed, Risser 0-2, primary curve magnitude from 20 to $40^{\circ}$, no prior treatment, and if female, either premenarchal or $<1$ year postmenarchal. Although primary curve magnitude from 25 to $40^{\circ}$ was expressed in SRS criteria, it was our treatment protocol to include immature patients who have progressive scoliosis from 20 to $40^{\circ}$, as a result we employed patients with Cobb angles from 20 to $24^{\circ}$, which is in accordance with a principle of Weinstein et al. [12]. Further, in SRS criteria, only patients who completed their brace treatment and were followed for more than 2 years after skeletal maturity were included. However, Negrini et al. [13] reported the fact that only $85 \%$ of patients reached the 2 years follow-up, but this subgroup was not different from the entire population for any basal characteristic nor any final results in their study. For this reason, we employed a follow-up of within 2 years beyond skeletal maturity to increase the number of patients available.

\section{Patient population}

From 1999 through 2010, 31 consecutive patients with AIS who were newly prescribed the OMC brace were studied. The study included 2 boys and 29 girls ranging in age from 10 years and 10 months to 14 years and 8 months, with a mean age of 12 years and 0 month. The type of curves consisted of thoracic in 4 cases, thoracolumbar in 4 cases, lumbar in 12 cases, double major in 7 cases, double thoracic in 1 case, and triple major in 3 cases. Risser stage was grade 0 in 20 cases, grade 1 in 5 cases, and grade 2 in 6 cases. Apexes of main curves were all lower than T7 (T8 in 5 cases, T9 in 6 cases, T10 in 3 cases, T11 in 1 case, T12 in 3 cases, L1 in 1 case, L2 in 8 cases, and L3 in 4 cases). The mean pre-brace Cobb angle of main curves was $27.3^{\circ}$, with the range from $21^{\circ}$ to $36^{\circ}$. The duration of brace treatment was from 3 years and 1 month to 6 years and 10 months, with a mean period of 4 years and 8 months. Of these, during brace wear follow-up times were from 1 year and 10 month to 6 years and 1 month, with a mean period of 3 years and 4 months. And post brace weaning follow-up times were from 0 month to 3 years and 3 months, with a mean period of 1 year and 4 months.

\section{Data collection and analysis}

We examined the initial in brace correction rate at the brace prescription, the clinical outcomes of main curves evaluated by curve progression and surgical rate, and the compliance evaluated by the instruction adherence rate for all cases. The estimated number of hours of brace wear in each patient was monitored by self-statement. And the instruction adherence rate was calculated to express the compliance. Curve flexibility was recognized by the hanging correction rate utilized hanging total spine $\mathrm{x}$-ray [8]. The brace correction rate, the hanging correction rate, and the instruction adherence rate were conducted by formulae as described below.

- Brace correction rate $(\%)=\{($ Cobb angle in upright position - Cobb angle on initial brace wear)/Cobb angle in upright position $\} \times 100$.

- Hanging correction rate $(\%)=\{$ (Cobb angle in upright position - Cobb angle in hanging position)/Cobb angle in upright position $\} \times 100$.

- Instruction adherence rate $(\%)=($ number of times to visit the outpatient clinic when the patient declared that he or she could wear the brace more than instructed hours minus 2 hours/all number of times to visit the outpatient clinic) $\times 100$.

The clinical outcome was assessed based on the SRS criteria. According to the Cobb angle on standing anteroposterior spine $\mathrm{x}$-rays that made with the patients out of the brace were classified as: (1) improved: decrease of the Cobb angle by $6^{\circ}$ or more, (2) stable: no more than $5^{\circ}$ of progression or improvement, (3) progressed: increase of the Cobb angle by $6^{\circ}$ or more, and (4) progression beyond the Cobb angle of $45^{\circ}$ who were considered candidates for surgery. All radiographic measurements were made by 1 author using the same protractor to minimize inter-observer variability in accordance with a concept of Lee et al. [6].

Statistical analyses were defined using a two-tailed paired $t$-test and chi square test. A value of $\mathrm{P}<0.05$ was considered statistically significant.

\section{Brace management protocol}

All OMC braces were fabricated by the same certified orthotist. A plaster cast was taken to capture the body shape of each patient, which was used by the certified orthotist to custom make each OMC brace. Then, not only the optimal correction but also comfortable fit and function consisted of pressure pad placements were ensured. Also, standing anteroposterior and lateral spine $\mathrm{x}$-rays were used to check the in brace correction and whole spinal alignment including pelvis while the brace was being worn.

Patients were instructed to wear the brace for a minimum of 20 hours per day at the beginning of brace treatment. When skeletal maturity was noted, that is, all of the following three criteria were fulfilled; a Risser stage of 4, at least 2 years passed since the onset of menstruation (for girls), two consecutive visits over a time period of at least 1 year with no more than a $1-\mathrm{cm}$ increase in height, the brace weaning started and the time in brace was slowly reduced during 1 year. Finally the brace wearing was stopped at 1 year post skeletal maturity. 


\section{Consent}

The study was approved by the University's Institutional Review Board and written informed consent was obtained from the patients and their parents prior to participating. And all procedures were in accordance with the Helsinki declaration.

\section{Results}

The average Cobb angles in upright position before treatment and at final follow-up were $27.3 \pm 4.2^{\circ}$ and $28.6 \pm 11.3^{\circ}$, respectively. As a result, the OMC brace could prevent curve progression during periods of growth (Figure 2). The average in brace Cobb angle on initial brace wear was $14.7 \pm 6.7^{\circ}$ and the average brace correction rate was $46.8 \pm 25.1 \%$. Meanwhile, the average Cobb angle in hanging position was $18.2 \pm 4.0^{\circ}$ and the average hanging correction rate was $33.0 \pm 14.1 \%$. The average brace correction rate was statistically better than the average hanging correction rate.

At final follow-up, the curve progressed in 10 cases, the curve improved in 6 cases, and the curve remained unchanged in 15 cases. The success rate of $67.7 \%$ (21/31) was achieved although the average instruction adherence rate was $53.7 \%$. Further, only 3 cases out of 31 progressed beyond the Cobb angle of $45^{\circ}$ were considered candidates for surgery. Therefore, the rate for progression to surgical indication was $9.7 \%(3 / 31)$. However, the cases were divided in two groups according to the instruction adherence rate, and as a result, the success rate was statistically higher in the patient group whose instruction adherence rate was greater than 50\% compared with in those $50 \%$ or less. The success rate in the patient group whose instruction adherence rate was $50 \%$ or less was $42.8 \%$. On the other hand, the success rate in the patient group whose instruction adherence rate was greater than
$50 \%$ was $88.2 \%$ (Figure 3 ). And the instruction adherence rates of 3 cases whose Cobb angles progressed beyond $45^{\circ}$ were all $50 \%$ or less $(0 \%, 0 \%$, and $42.9 \%)$.

\section{Illustrative cases presentation}

\section{Case 1: 12 years 10 months girl}

The patient presented a left convex $23^{\circ}$ lumbar scoliosis before treatment. The Cobb angle of the lumbar curve in hanging position was $18^{\circ}$. An in-OMC brace $\mathrm{x}$-ray of the patient was demonstrated $5^{\circ}$ due to correction created by the pressure pad pushing the apex of L2 between T12 and pelvis. Her instruction adherence rate was maintained at the $100 \%$ throughout brace treatment for 3 years 5 months. At final follow-up, the Cobb angle improved to $7^{\circ}$ (Figure 4).

\section{Case 2: 11 years 3 months girl}

The patient presented a left convex $26^{\circ}$ thoracic scoliosis before treatment. The Cobb angle of the thoracic curve in hanging position was $17^{\circ}$. An in-OMC brace $\mathrm{x}$-ray of the patient was demonstrated $13^{\circ}$ due to correction created by the pressure pad pushing the apex of $\mathrm{T} 8$ between $\mathrm{T} 5$ and $\mathrm{T} 11$. Her instruction adherence rate was remained at the only $7.7 \%$ throughout brace treatment for 6 years 5 months. At final follow-up, the Cobb angle progressed to $41^{\circ}$ (Figure 5).

\section{Discussion}

Skeletally immature patients with AIS are at risk for curve progression together with growing. Thus, the main goal of brace treatment in AIS is to change the natural history by stopping curve progression. Brace treatment has been growing more and more important because the discovery rate of AIS in an early stage has been presently increased owning to the well-established periodic school

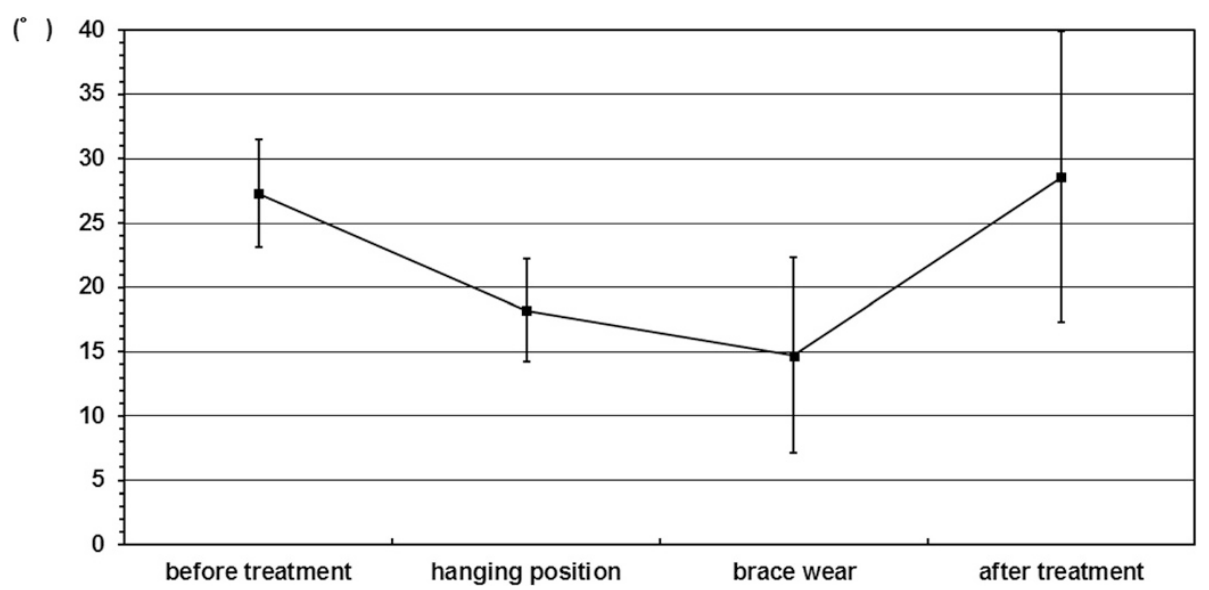

Figure 2 Sequential changes of the Cobb angle. The average Cobb angles in upright position before treatment, in hanging position, on initial brace wear, and at final follow-up were $27.3 \pm 4.2^{\circ}, 18.2 \pm 4.0^{\circ}, 14.7 \pm 6.7^{\circ}$, and $28.6 \pm 11.3^{\circ}$, respectively. The main curves were corrected by wear of the OMC brace better than hanging position. And OMC brace treatment could prevent the progression of curves during periods of growth. 


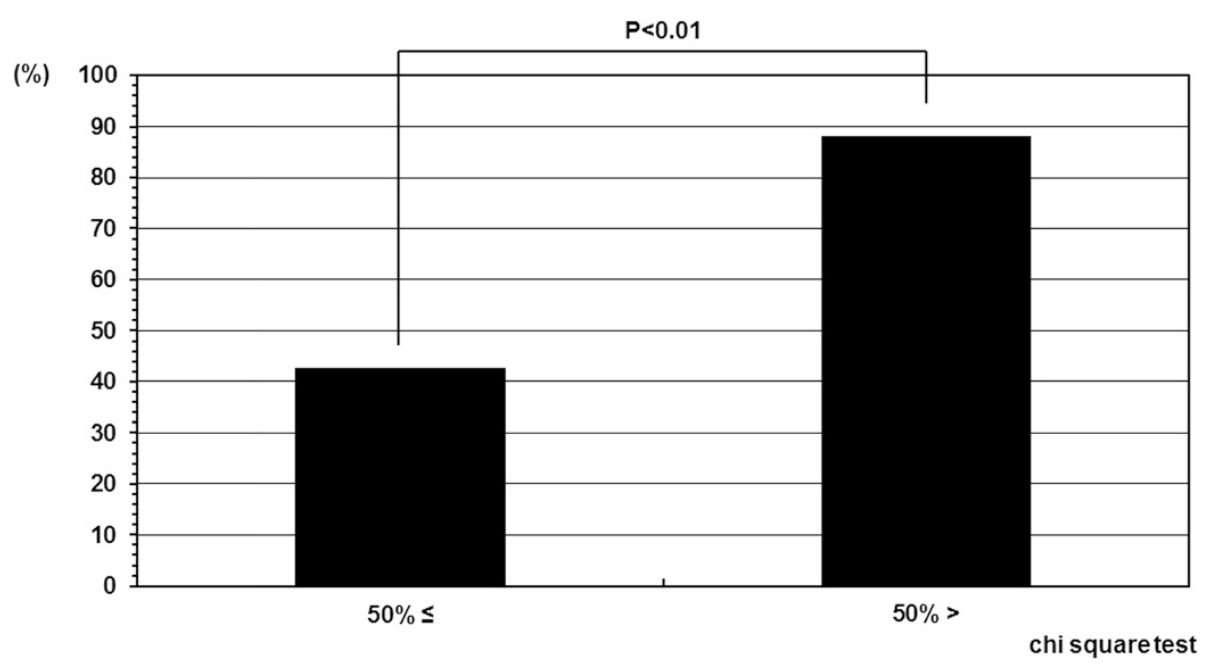

Figure 3 Success rate depend on compliance. The success rate in the patient group whose instruction adherence rate was greater than 50\% and $50 \%$ or less were $88.2 \%$ and $42.8 \%$, respectively. The success rate was statistically higher in the patient group whose instruction adherence rate was greater than $50 \%$ as compared with in those $50 \%$ or less.

screening [14]. Current recommendations from the SRS include the initiation of brace treatment in skeletally immature patients who present with curves greater than $30^{\circ}$ on initial presentation or in patients who progress greater than $10^{\circ}$ to a magnitude greater than $25^{\circ}[15]$.

According to Lonstein and Carlson [16], 68\% of patients with a Risser stage of 0 or 1 progressed greater than $5^{\circ}$ for curve between $20^{\circ}$ and $29^{\circ}$. Bunnell [17] also reported progression of at least $5^{\circ}$ in $68 \%, 10^{\circ}$ in $34 \%$, and $20^{\circ}$ in $18 \%$ patients in his series. Further, patients diagnosed before 10 years had an $88 \%$ risk of progression of $5^{\circ}$ or more and this risk was the same for those diagnosed between the ages of 10 and 12. Weinstein et al. [18] followed curves for an average of 40 years and nearly $70 \%$ of curves measuring a minimum of $30^{\circ}$ progressed after skeletal maturity. Similarly, Nachemson et al. [4] demonstrated $66 \%$ of observed patients with idiopathic scoliosis curves measuring $20^{\circ}$ to $35^{\circ}$ progressed $6^{\circ}$. Karol et al. [19] found 32\% of boys presenting with a curve of at least $25^{\circ}$ and all Risser stages progressed $10^{\circ}$ or more. To be considered an effective management method, Janicki et al. [20] stated that a brace must prevent progression in at least $70 \%$ of patients with AIS. In this study, $67.7 \%$ patients achieved curve progression of less



a

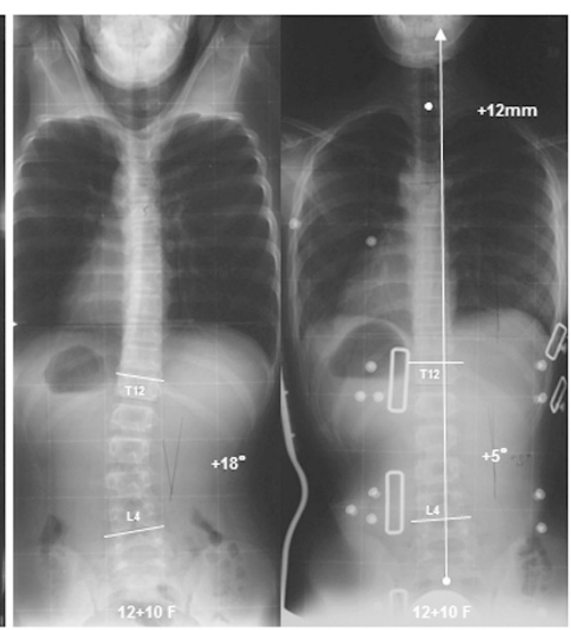

d

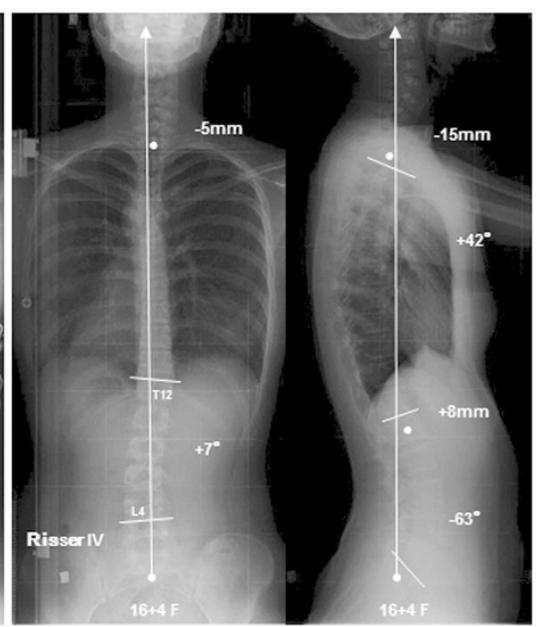

f

Figure 4 Case 1: 12 years 10 months girl. The patient had a left convex $23^{\circ}$ lumbar scoliosis before treatment (a, $\left.\mathbf{b}\right)$. The angles of lumbar curves were corrected to $18^{\circ}$ in hanging position and $5^{\circ}$ in brace wear, respectively (c, d). Throughout brace treatment for 3 years and 5 months, her instruction adherence rate was maintained at 100\%, and the Cobb angle improved to $7^{\circ}$ at final follow-up (e, f). 


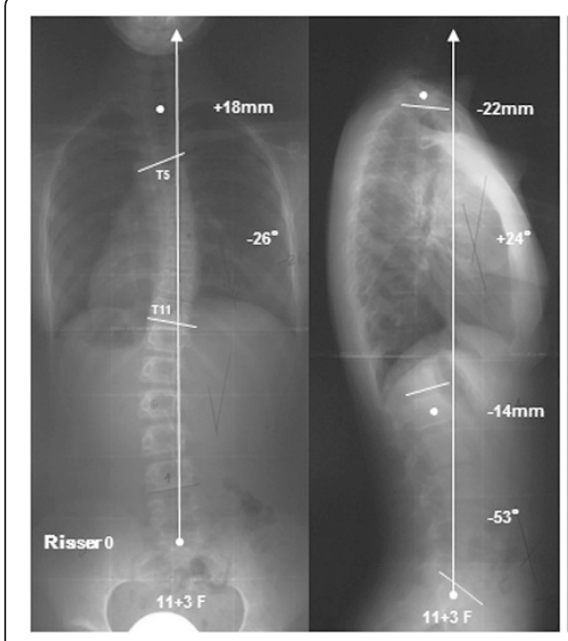

a

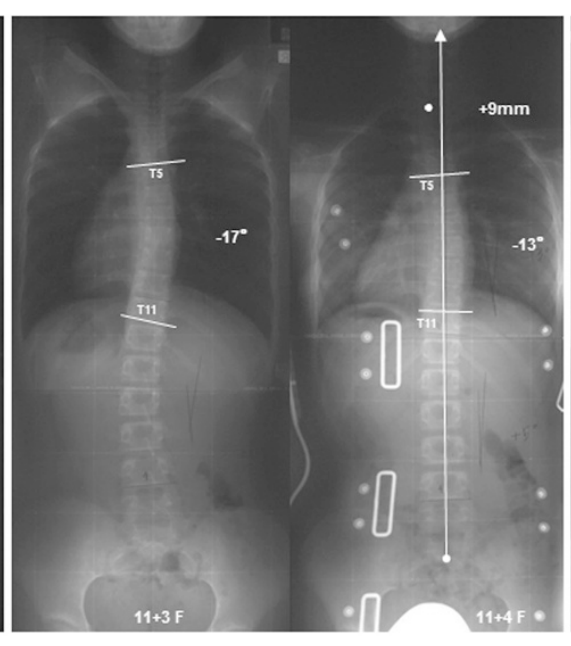

C

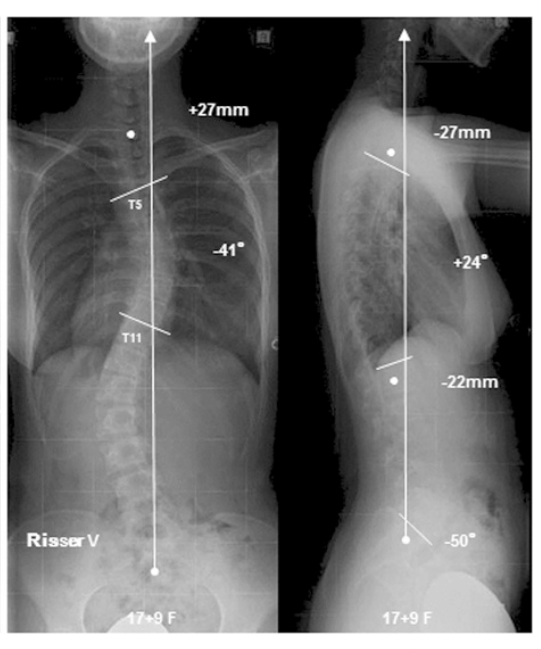

e

f

Figure $\mathbf{5}$ Case 2: 11 years $\mathbf{3}$ months girl. The patient had a right convex $26^{\circ}$ thoracic scoliosis before treatment (a, b). The angles of thoracic curves were corrected to $17^{\circ}$ in hanging position and $13^{\circ}$ in brace wear, respectively (c, d). Throughout brace treatment for 6 years and 5 months, her instruction adherence rate remained at only $7.7 \%$, and the Cobb angle progressed to $41^{\circ}$ at final follow-up (e, f).

than $6^{\circ}$ at the skeletal maturity. Further, only $9.7 \%$ patients reached Cobb angle of more than $45^{\circ}$ which meant surgical indication. These results verified that OMC brace treatment could change the natural history of AIS just like as other TLSOs previously reported [6,10,13,20-25] (Table 1).

With regard to ability of curve correction, the average initial in brace correction of the OMC brace was $46.8 \%$. This was inferior to the Charleston bending brace but almost same as other TLSOs [26-36] (Table 2). Although the OMC brace is a TLSO, correction and controlling of the upper curve in double thoracic scoliosis could be achieved to utilize the righting reflex that was generated by the active bending for the high thoracic curve under bracing [7].
The amount of time spent in the brace during the active phase has been still under debate. Blount et al. [37] originally described full-time brace wear as 23 hours a day and Rowe et al. [5] found that bracing for 23 hours a day was the most successful means in their meta-analysis. Aulisa et al. [38] also stated that wearing the brace only overnight was associated with a high rate of curve progression. Indeed, the guidelines released by the Society on Scoliosis Orthopaedic and Rehabilitation Treatment (SOSORT) indicate adherence as a key element in determining the efficacy of bracing [15]. However, some other studies reported successful treatment with part-time brace wear as 16 hours a day [39,40]. Schiller et al. [41] stated part-time or nighttime bracing (Charleston, Providence) may be effective for curves less than $35^{\circ}$; however, curves

Table 1 Literature review of the clinical results under SRS criteria

\begin{tabular}{|c|c|c|c|c|}
\hline Author (Year) & Treatment period & Type of brace & Success rate & $\begin{array}{l}\text { Progression rate for } \\
\text { surgical indication }\end{array}$ \\
\hline Coillard C et al. (2007) [10] & $?$ & SpiceCorBrace & $59.4 \%^{* *}$ & $24.1 \%^{+}$ \\
\hline \multirow[t]{2}{*}{ Janicki JA et al. (2007) [20] } & $1 \mathrm{y} 5 \mathrm{~m}$ & TLSO & $85.4 \%{ }^{*}$ & $62.4 \%^{+}$ \\
\hline & $1 \mathrm{y} 4 \mathrm{~m}$ & Providence & $68.6 \%^{*}$ & $42.9 \%^{+}$ \\
\hline Negrini S et al. (2009) [13] & $4 y 2 m$ & Lyon, SPoRT & $95.8 \%{ }^{* *}$ & $0.0 \%^{+}$ \\
\hline Aulisa AG et al. (2009) [21] & $4 y 11 \mathrm{~m}$ & Progressive Action Short Brace & $100.0 \%{ }^{*}$ & $0.0 \%^{+}$ \\
\hline Zaborowska-Sapeta K et al. (2011) [22] & $2 y 8 m$ & Chêneau brace & $48.1 \%{ }^{*}$ & $12.7 \% \%^{++}$ \\
\hline Lee CS et al. (2012) [6] & $2 y 9 m$ & Chaleston Bending Brace & $84.2 \%{ }^{* *}$ & $12.6 \%^{+}$ \\
\hline Aulisa AG et al. (2012) [23] & $3 y 6 m$ & Progressive Action Short Brace & $100.0 \%{ }^{*}$ & $0.0 \%^{+}$ \\
\hline Weinstein SL et al. (2013) [12,24] & $?$ & TLSO & - & $28.1 \%^{++}$ \\
\hline Maruyama T et al. (2013) [25] & $1 \mathrm{y} 9 \mathrm{~m}$ & Rigo-Chêneau brace & $70.8 \%{ }^{* *}$ & $18.2 \%^{+}$ \\
\hline Kuroki H et al. (2015) [current report] & $3 y 4 m$ & Osaka Medical College Brace & $67.7 \%{ }^{* *}$ & $9.7 \%^{+}$ \\
\hline
\end{tabular}

" progression $<5^{\circ},{ }^{* *}$ progression $<6^{\circ},{ }^{+}$progression $\geq 45^{\circ},++$ progression $\geq 50^{\circ}$. 
Table 2 Literature review of the initial correction rate

\begin{tabular}{llll}
\hline Author (Year) & Apex & Type of brace & Correction rate \\
\hline Watts HG et al. (1977) [26] & below T10 & Boston Brace & $54.7 \%$ \\
Uden A et al. (1982) [27] & below T7 & Boston Brace & $41.0 \%$ \\
& & Milwaukee Brace & $10.0 \%$ \\
Jonasson-Rajala E et al. (1984) [28] & below T8 & Boston Thoracic Brace & $46.2 \%$ \\
& & Boston Milwaukee Brace & $29.3 \%$ \\
Ohta K et al. (1988) [29] & - & Boston Brace & $36.9 \%$ \\
Kawakami N et al. (1991) [30] & - & Active Correction Brace & $53.8 \%$ \\
Asazuma T et al. (1991) [31] & below T7 & Active Correction Brace & $17.6 \%$ \\
Arai S et al. (1992) [32] & - & Milwaukee Brace & $23.0 \%{ }^{*}$ \\
Iwaya D et al. (1997) [33] & below T7 & $44.2 \%{ }^{*}$ \\
Semoto Y et al. (1999) [34] & below T7 & Charleston Bending Brace & $75.0 \%$ \\
Spoonamore MJ et al. (2001) [35] & - & OMC Brace & $35.5 \%$ \\
D'Amato CR et al. (2004) [36] & - & Rosenberger Brace & $30.0 \%$ \\
Kuroki H et al. (2015) [current report] & Providence Brace & $96.0 \%$ \\
\hline
\end{tabular}

${ }^{*}$ maximum correction rate.

greater than $35^{\circ}$ often require full-time bracing to reliably limit curve progression. Weinstein et at [24] indicated brace wear for an average of at least 12.9 hours a day was associated with success rate of 90 to $93 \%$. In our previous study, there was statistical difference between 7-12 hours and 13-18 hours a day but no statistical difference between 13-18 hours and 19-24 hours a day [42]. So, at least 13 hours in brace a day is basically supposed to be mandatory to halt progression of curves.

As the documented problems of brace treatment, compliance, drop out, and psychological stress have been previously emphasized and investigated by many authors. Especially, compliance appears to be the greatest concern for any treating physician and the primary cause for poor results from brace treatment. However, it is not so easy to keep brace wear as scheduled in most adolescent patients. Gepstein et al. [43] showed that in all cases, patients or their parents reported the Charleston bending brace was worn for at least $80 \%$ of the prescribe time, yet DiRaimondo et al. [44] stated that only $15 \%$ of patients were highly compliant. Nicolson et al. [45] also used temperature data loggers at the brace-skin interface to measure time in the brace and found patients overestimated their time in brace nearly $150 \%$. In current study, the instruction adherence rate was only 53.7\% even under self-statement. The drop out rates in the literatures were from 20 to $40 \%$ [46-52]. In our past study, the drop out rate was held about 18.5\% [42]. With respect to the psychological stress, Climent et al. [53] told that the brace treatment showed an impact on the overall quality of life. Matsunaga et al. [54] showed the rate of patients with psychological problems increased from $7.6 \%$ to $82.1 \%$ at 1 month after the start of brace treatment. Further, MacLean et al. [55] mentioned about the psychological effects of brace wear treatment for not only the patients themselves but also their parents. These are truly key points for success of brace treatment. Therefore, it is important to relieve the emotional stress during brace treatment as much as possible by mental support for AIS patients on frequent and periodic consultation (once every 3 to 6 months depending on the condition of each case). Thereby, brace wear can be facilitated and the brace treatment will be maintained as scheduled.

There are several limitations in this study. First, this project was small sample size. Second long-term follow-up was missing. Third, compliance of the patients was low, that is, the average instruction adherence rate of our subject was only $53.7 \%$ although it was subjectively obtained due to the lack of an objective compliance monitor in the braces. A prospective long-term study with larger sample size consisted of sufficient compliant patients is suggested in order to draw a solid conclusion. However, we believe that our study will contribute some improvement for the future management of AIS because accumulation of these minor data based on clinical experiences from a great number of institutions must be essential to the future solution of issues regarding efficacy of brace treatment for AIS.

In conclusion, OMC brace treatment for AIS in the skeletally immature patients could alter the natural history and significantly decreased the progression of curves to the threshold for surgical intervention. Brace compliance was associated with greater success in this study. By a great deal of care for AIS patients 
at the periodic consultations, motivation for brace wear must be inspired and it will consequently lead to an acceptable clinical outcome, that is, not only physically but also emotionally balanced body with Cobb angle under $45^{\circ}$.

\section{Competing interests}

The authors declare that they have no competing interests.

\section{Authors' contributions}

HK conception and design, acquisition of data, analysis and interpretation data. $\mathrm{NI}$ acquisition of data. $\mathrm{HH}$ acquisition of data. $\mathrm{KH}$ acquisition of data. EC analysis and interpretation data. NT analysis and interpretation data. All authors read and approved the final manuscript.

\section{Author details}

'Department of Orthopaedic Surgery, National Hospital Organization Miyazaki Higashi Hospital, 4374-1 Tayoshi Ooaza, Miyazaki 880-0911, Japan. ${ }^{2}$ Department of Orthopaedic Surgery, University of Miyazaki Faculty of Medicine, Miyazaki, Japan. ${ }^{3}$ Department of Orthopaedic Surgery, Nozaki Higashi Hospital, Miyazaki, Japan.

\section{Received: 20 January 2015 Accepted: 19 March 2015}

\section{Published online: 11 April 2015}

\section{References}

1. Cotrel Y, Dubousset J, Guilaumat M. New universal instrumentation in spinal surgery. Clin Orthop. 1988;227:10-23.

2. Asher MA, Strippgen WE, Heinig CF, Carson WL. Isola spinal implant system: principles, design, and applications. In: An HS, Cotler JM, editors. Spinal instrumentation. Baltimore, MD: Williams \& Wilkins; 1992. p. 325-51.

3. Kaneda K, Shono Y, Satoh S, Abumi K. New anterior instrumentation for the management of thoracolumbar and lumbar scoliosis: application of the Kaneda two-rod system. Spine. 1996;21:1250-62.

4. Nachemson AL, Peterson LE. Effectiveness of treatment with a brace in girls who have adolescent idiopathic scoliosis. J Bone Joint Surg. 1995;77A:815-22.

5. Rowe DE, Bernstein SM, Riddick MF, Adler F, Emans JB, Gardner-Bonneau D. A meta-analysis of the efficacy of non-operative treatments for idiopathic scoliosis. J Bone Joint Surg. 1997;79A:664-74.

6. Lee CS, Hwang CJ, Kim DJ, Kim JH, Kim YT, Lee MY, et al. Effectiveness of the Charleston night-time bending brace in the treatment of adolescent idiopathic scoliosis. J Pediatr Orthop. 2012;32:368-72.

7. Endo O, Onomura T, Yamamoto S, Yamaguchi R, Kato M, Watanabe H, et al. Scoliosis treatment with the Osaka Medical College type brace (OMC-brace). In: Itami Y, Nishio A, editors. Seikeigeka Mook 18. Tokyo, Japan: Kanehara syuppan Inc; 1981. p. 134-49. in Japanese, the title is literally translated.

8. Kuroki H, Inomata N, Hamanaka H, Chosa E, Tajima N. Significance of hanging total spine $\mathrm{x}$-ray to estimate the indicative correction angle by brace wearing in idiopathic scoliosis patients. Scoliosis. 2012;7:8.

9. Katz DE, Herring JA, Browne RH, Kelly DM, Birch JG. Brace wear control of curve progression in adolescent idiopathic scoliosis. J Bone Joint Surg. 2010;92A:1343-52.

10. Coillard C, Vachon V, Circo AB, Beauséjour M, Rivard CH. Effectiveness of the SpineCor brace based on the new standardized criteria proposed by the Scoliosis Research Society for adolescent idiopathic scoliosis. J Pediatr Orthop. 2007;27:375-9.

11. Richards BS, Bernstein RM, D'Amato CR, Thompson GH. Standardization of criteria for adolescent idiopathic scoliosis brace studies: SRS Committee on Bracing and Nonoperative Management. Spine. 2005;30:2068-75.

12. Weinstein SL, Dolan LA, Wright JG, Dobbs MB. Design of the bracing in adolescent idiopathic trial (BrAIST). Spine. 2013;38:1832-41.

13. Negrini S, Atanasio S, Fusco C, Zaina F. Effectiveness of complete conservative treatment for adolescent idiopathic scoliosis (bracing and exercises) based on SOSORT management criteria: results according to the SRS criteria for bracing studies - SOSORT award 2009 winner. Scoliosis. 2009:4:19.

14. Kuroki H, Goto E, Kurihara N, Tajima N. The conditions and problems of our scoliosis clinic for the past 5 years. J Miyazaki M A. 2004;28:48-53. in Japanese, the title is literally translated.
15. Negrini S, Aulisa AG, Aulisa L, Circo AB, De Mauroy JC, Durmala J, et al. 2011 SOSORT guidelines; orthopaedic and rehabilitation treatment of idiopathic scoliosis during growth. Scoliosis. 2012;7:3.

16. Lonstein JE, Carlson JM. The prediction of curve progression in untreated idiopathic scoliosis during growth. J Bone Joint Surg. 1984;66A:1061-71.

17. Bunnell WP. The natural history of idiopathic scoliosis. Clin Orthop Relat Res. 1988;229:20-5

18. Weinstein SL, Ponseti IV. Curve progression in idiopathic scoliosis. J Bone Joint Surg. 1983;65A:447-55.

19. Karol LA, Johnston 2nd CE, Browne RH, Madison M. Progression of the curve in boys who have idiopathic scoliosis. J Bone Joint Surg. 1993;75A:1804-10.

20. Janicki JA, Poe-Kochert C, Armstrong DG, Thompson GH. A comparison of the thoracolumbosacral orthoses and Providence orthosis in the treatment of adolescent idiopathic scoliosis: results using the new SRS inclusion and assessment criteria for bracing studies. J Pediatr Orthop. 2007;27:369-74.

21. Aulisa AG, Guzzanti V, Galli M, Perisano C, Falciglia F, Aulisa L. Treatment of thoraco-lumbar curves in adolescent females affected by idiopathic scoliosis with a progressive action short brace (PASB): assessment of results according to the SRS committee on bracing and nonoperative management standardization criteria. Scoliosis. 2009:4:21.

22. Zaborowska-Sapeta K, Kowalski IM, Kotwicki T, Protasiewicz-Faldowska H, Kiebzak W. Effectiveness of Chêneau brace treatment for idiopathic scoliosis: prospective study in 79 patients followed to skeletal maturity. Scoliosis. $2011 ; 6: 2$.

23. Aulisa AG, Guzzanti V, Perisano C, Marzetti E, Falciglia F, Aulisa L. Treatment of lumbar curves in scoliotic adolescent females with progressive action short brace; a case series based on the Scoliosis Research Society committee criteria. Spine. 2012;37:E786-91.

24. Weinstein SL, Dolan LA, Wright JG, Dobbs MB. Effects of bracing in adolescents with idiopathic scoliosis. N Engl J Med. 2013;369:1512-21.

25. Maruyama T, Yamada H, Kobayashi Y, Nakao Y, Sakai H. Outcomes of Rigo-Chêneau type brace treatment for adolescent idiopathic scoliosis: using the Scoliosis Research Society brace studies standardization protocol. J Jpn Orthop Assoc. 2013;87:S99 (in Japanese).

26. Watts $H G$, Hall JE, Stanish W. The Boston brace system for the treatment of low thoracic and lumbar scoliosis by the use of a girdle without superstructure. Clin Orthop. 1977;126:87-92.

27. Udén A, Willner S, Pettersson H. Initial correction with the Boston thoracic brace. Acta Orthop Scand. 1982;53:907-11.

28. Jonasson-Rajala E, Josefsson E, Lundberg B, Nilsson H. Boston thoracic brace in the treatment of idiopathic scoliosis: initial correction. Clin Orthop. 1984;183:37-41.

29. Ohta K, Ikata T, Shinohara K, Teramae T, Nishioka T, Kasai T. An active corrective brace for early idiopathic scoliosis. J Jpn Scoliosis Soc. 1988;3:196-9 (in Japanese).

30. Kawakami N, Mimatsu K, Katoh F, Saito H, Satou K, Yagi R. Evaluation of the Cobb angle and vertebral rotation in brace treatment of idiopathic scoliosis. J Jpn Scoliosis Soc. 1991;6:31-4 (in Japanese).

31. Asazuma T, Suzuki N, Ono T, Tezuka M, Hijikata S, Hirabayashi K. Follow-up study of under-arm brace treatment to adolescent idiopathic scoliosis. J Jpn Scoliosis Soc. 1991;6:22-6 (in Japanese).

32. Arai $S$, Ootsuka $Y$, Kitahara H, Minami S, Moriya H, Nakata Y, et al. Brace treatment for idiopathic scoliosis: followed over 10 years. J Jpn Scoliosis Soc. 1992;7:83-7 (in Japanese).

33. Iwaya D, Ohtake S, Harata S, Ueyama K, Itoh J, Nitobe T. Treatment for idiopathic scoliosis with Charleston bending brace; preliminary study. J Jpn Scoliosis Soc. 1997;12:30-3 (in Japanese).

34. Semoto Y, Kosaka R, Yamada M, Abe M. Osaka medical college type brace for idiopathic scoliosis. J Jpn Orthop Assoc. 1999;73:S146 (in Japanese).

35. Spoonamore MJ, Dolan LA, Weinstein SL. Use of the Rosenberger brace in the treatment of progressive adolescent idiopathic scoliosis. Spine. 2004;29:1458-64

36. D'Amato CR, Griggs S, McCoy B. Nighttime bracing with the Providence brace in adolescent girls with idiopathic scoliosis. Spine. 2001;26:2006-12.

37. Blount WP, Moe JH. The Milwaukee brace, ed 2. Baltimore, MD: Williams \& Wilkins; 1980.

38. Aulisa AG, Giordano M, Falciglia F, Marzetti E, Poscia A, Guzzanti V. Correlation between compliance and brace treatment in juvenile and adolescent idiopathic scoliosis; SOSORT 2014 award winner. Scoliosis. 2014;9:6. 
39. Allington NJ, Bowen JR. Adolescent idiopathic scoliosis: treatment with the Wilmington brace. a comparison of full-time and part-time use. J Bone Joint Surg. 1996;78A:1056-62.

40. Green NE. Part-time bracing of adolescent idiopathic scoliosis. J Bone Joint Surg. 1986;68A:738-42.

41. Schiller JR, Thakur NA, Eberson CP. Brace management in adolescent idiopathic scoliosis. Clin Orthop Relat Res. 2010;468:670-8.

42. Kuroki H, Kumon T, Goto E, Kubo S, Chosa E, Tajima N. Treatment for Idiopathic Scoliosis with the Osaka Medical College (OMC) Brace. Kansas City, KS, USA: Presented in Harrington Spine Symposium; 2005.

43. Gepstein R, Leitner Y, Zohar E, Angel I, Shabat S, Pekarsky I, et al Effectiveness of the Charleston bending brace in the treatment of single-curve idiopathic scoliosis. J Pediatr Orthop. 2002;22:84-7.

44. DiRaimondo CV, Green NE. Brace-wear compliance in patients with adolescent idiopathic scoliosis. J Pediatr Orthop. 1988:8:143-6.

45. Nicholson GP, Ferguson-Pell MW, Smith K, Mchir ME, Morley T. The objective measurement of spinal orthosis use for the treatment of adolescent idiopathic scoliosis. Spine. 2003;28:2243-51.

46. Carr WA, Moe JH, Winter RB, Lonstein JE. Treatment of idiopathic scoliosis in the Milwaukee brace: long-term results. J Bone Joint Surg. 1980;62A:599-612.

47. Asaka Y, Yamauchi Y, Tsuji T, Kubo T, Yamaguchi T, Nakagawa $H$. The results of under-arm brace treatment for the patients of idiopathic scoliosis. J Jpn Scoliosis Soc. 1989:4:154-8 (in Japanese).

48. Kikuchi K, Hayashi K, Shinoto A, Manabe S, Yamane Y, Inoue K. Brace therapy in idiopathic scoliosis: results and problems. J Jpn Scoliosis Soc. 1988;3:116-9 (in Japanese).

49. Morishima T, Iwasaki M, Akita M. A study of drop out from brace treatment for patients with idiopathic scoliosis. J Jpn Scoliosis Soc. 2000;15:62-5 (in Japanese).

50. Ohtake S, Nasu K, Harata S, Oomi Y, Suetsuna F, Kudo O, et al. Acceptance of braces in patients with scoliosis. J Jpn Scoliosis Soc. 1988;3:100-2 (in Japanese).

51. Price CT, Scott DS, Reed FR, Riddick MF. Nighttime bracing for adolescent idiopathic scoliosis with the Charleston bending brace: long-term follow-up. J Pediatr Orthop. 1997:17:703-7.

52. Uchiyama S, Nakayama T, Okumura H, Koga Y, Honma T, Takahashi H. Problems in brace treatment of scoliosis: from the study of "drop out" cases. J Jpn Scoliosis Soc. 1993;8:64-6 (in Japanese).

53. Climent JM, Sánchez J, the group for the study of quality of life in spine deformities. Impact of the type of brace on the quality of life of adolescents with spine deformities. Spine. 1999;24:1903-8.

54. Matsunaga S, Hayashi K, Naruo T, Nozoe S, Komiya S. Psychologic management of brace therapy for patients with idiopathic scoliosis. Spine. 2005:30:547-50

55. MacLean WE, Green NE, Pierre CB, Ray DC. Stress and coping with scoliosis: psychological effects on adolescents and their families. J Pediatr Orthop. 1989;9:257-61.

\section{Submit your next manuscript to BioMed Central and take full advantage of:}

- Convenient online submission

- Thorough peer review

- No space constraints or color figure charges

- Immediate publication on acceptance

- Inclusion in PubMed, CAS, Scopus and Google Scholar

- Research which is freely available for redistribution 